\title{
NEW RECORDS FOR THE NEMATODES ASCARIDIA COLUMBAE (GMELIN) TRAVASSOS, ACUARIA MAYORI LENT, FREITAS \& PROENÇA AND APROCTELLA STODDARDI CRAM IN BRAZILIAN BIRDS, WITH REDESCRIPTION OF THE SPECIES
}

\author{
R. Magalhães Pinto 1,3 \\ J. Júlio Vicente ${ }^{1}$ \\ Dely Noronha 1 \\ Sueli P. de Fábio ${ }^{2,3}$
}

\begin{abstract}
The species Ascaridia columbae (Gmelin, 1790) Travassos, 1913, Acuaria mayori Lent, Freitas \& Proença, 1945 and Aproctella stoddardi Cram, 1931, are redescribed and referred in new hosts. Acuaria mayori is reported for the first time in Brazil and Ap. stoddardi in South America. Ascaridia columbae is properly figured for the first time in Brazil.

KEY WORDS. Nematoda, endoparasites, brazilian birds
\end{abstract}

Studies regarding avian endoparasites have been currently reported since these hosts are subject of great interest, either for economical or general conservation purposes, considering the role they play in the environment. Nematodes recovered from birds, of three families - Columbidae, Fringillidae and Thraupidae - are herein presented.

\section{MATERIAL AND METHODS}

Samples were recovered from hosts and placed into a $0,85 \% \mathrm{NaCl}$ solution, fixed and preserved in a Railliet \& Henry's solution. Specimens were dehydrated in ethanol $\left(70^{\circ}-100^{\circ} \mathrm{GL}\right)$; a few were stained in alcoholic carmine and most of them studied unstained, cleared in beechwood creosote and preserved in balsam as whole mounts. All specimens were deposited in the Instituto Oswaldo Cruz Helminthological Collection (CHIOC). Measurements are in micrometers unless otherwise indicated.

1) Departamento de Helmintologia, Instituto Oswaldo Cruz, Caixa Postal 926, 21045-900 Rio de Janeiro, Rio de Janeiro, Brasil.

2) Departamento de Biologia Animal, Universidade Federal Rural do Rio de Janeiro, 23851-970 Seropédica, Rio de Janeiro, Brasil.

3) Research fellows CNPq. 


\section{RESULTS}

\section{Ascaridiidae Travassos, 1919 \\ Ascaridia columbae (Gmelin, 1790) Travassos, 1913 \\ Figs 1-3, 6}

Redescription (based on four mature males and three mature females). General: cuticular lateral flanges generally present. Lips without interlabia. Esophagus club-shaped, without posterior bulb.

Male (Figs 1,3,6): 24,22-28,22mm long, 780-850 wide. Esophagus $1,80-2,17 \mathrm{~mm}$ long. Nerve ring $490-580$ and excretory pore $580-840$ from anterior end, respectively. Precloacal chitinous-rimmed sucker 180-210 in diameter, 210-260 from cloacal aperture and 580-720 from posterior extremity. Spicules equal or slightly subequal, similar $1,80-1,90$ long. Thirteen pairs of caudal papillae, five precloacal and eight postcloacal. Cloacal aperture 360-460 from posterior end.

Female (Fig. 2): 34,55-42,33mm long, 0,88-1,02mm wide. Esophagus 2,17-2,21 mm long. Nerve ring 630-670 and excretory pore 770-910 from anterior end, respectively. Vulva $17,34-19,04 \mathrm{~mm}$ from anterior extremity; ovijector 560-780 long. Eggs 72 long by 43-46 wide. Rectum 440-630 long. Anus $0,91-1,12 \mathrm{~mm}$ from posterior end.

Taxonomic summary:

Host - Streptopelia risoria (Linnaeus) (=Columba risoria Linnaeus), Columbidae $($ Common name $=$ Collared turtle-dove, pomba de coleira).

Site - intestine.

Locality - State of Rio de Janeiro, Brazil.

Specimens deposited - CHIOC no. 32,823 a-c (whole mounts); 32,902 (wet material).

Remarks: In spite of its wide geographical distribution, this species, althoug referred previously ocurring in Brazil, was poorly figured (male caudal extremity) only at the beginning of the century (TRAVASSOS, 1913). The most reliable remarks regarding the distribution of caudal papillae in males of $A$. columbae are those of BAYLIS \& DAUBNEY (1922), when the species was recorded in Crocopus phoenicopterus, Phlogoenas luzonica (sic) and other pigeons from India. Streptopelia risoria (Linnaeus) is a new host record for $A$. columbae in Brazil. This species was previously reported in Columba livia dom. (Linnaeus) and, more recently, in Leptotila r. rufaxila (Richard \& Bernard, 1712) from Amapa (PINTO \& GOMES, 1985).

Acuariidae Seurat, 1913

Acuaria mayori Lent, Freitas \& Proença, 1945

Figs 4, 5, 7

Redescription (based on two mature males and two mature females). General: anterior extremity without cuticular thickenings or shields but with four 


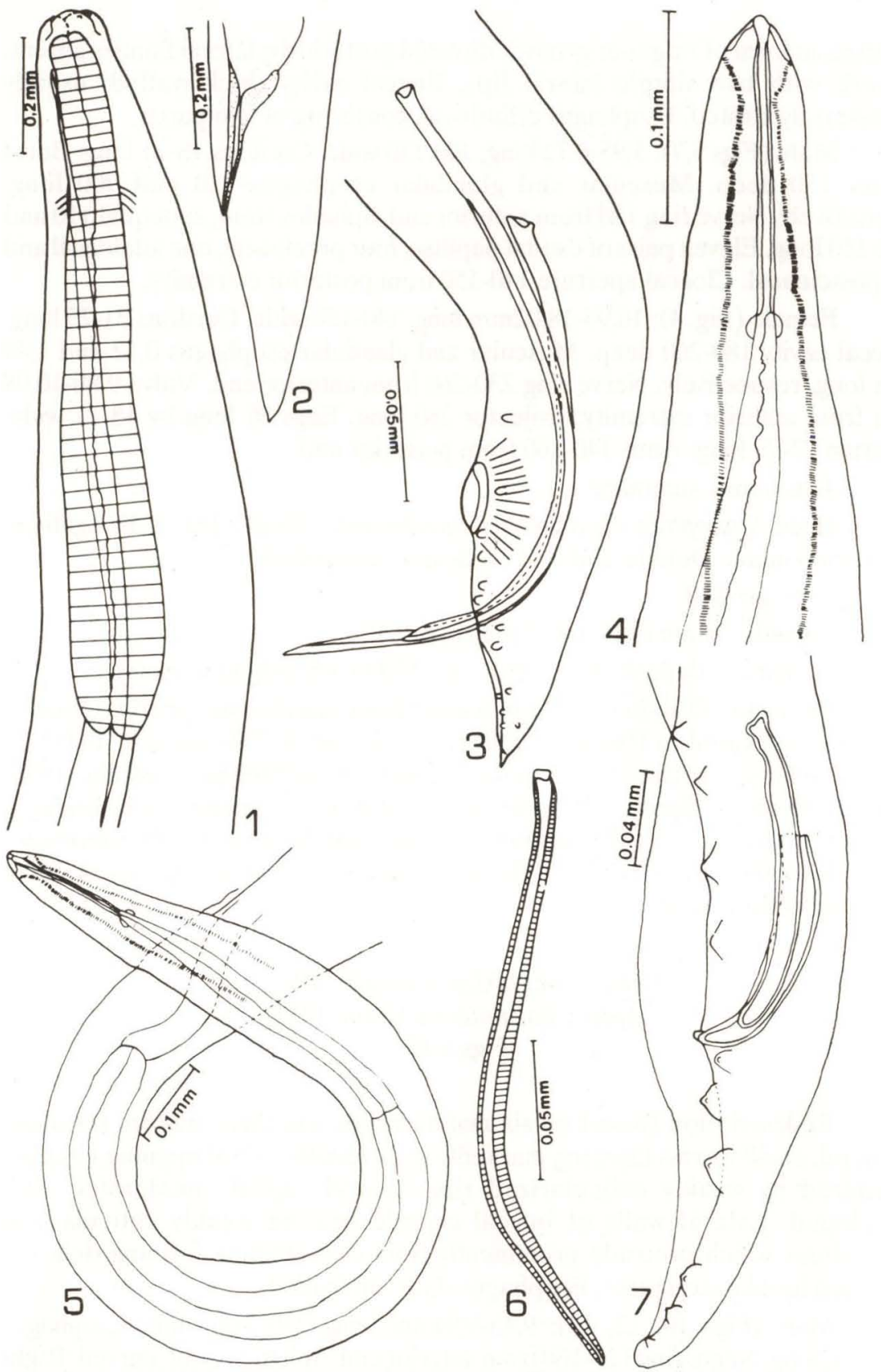

Figures 1-7. Ascaridia columbae. (1) male, anterior portion, lateral view; (2) female, posterior end, lateral view; (3) male, posterior portion, lateral view; (6) spicule, frontal view. Acuaria mayori. (4)female, anterior portion, lateral view; (5) male, anterior portion, lateral view; (7) male, posterior portion, lateral view. 
cordons in form of ridges or grooves directed posteriorly; lateral flanges absent. Mouth with two simple lateral lips. Buccal cavity thick walled, usually transversely strated. Esophagus cylindrical, consisting of two parts.

Male (Figs 5,7): 5,95-6,72 long, 100-120 wide. Cordons 18-21 long. Bucal cavity 150 deep. Muscular and glandular esophagus 410 and 900 long, respectively. Nerve ring 180 from anterior end. Spicules stout, subequal 110 and 140-150 long. Eleven pairs of caudal papillae, four precloacal, one adcloacal and six postcloacal. Cloacal aperture 140-150 from posterior extremity.

Female (Fig. 4): 16,96-18,02mm long, 140-150 wide. Cordons 21-25 long. Buccal cavity 180-200 deep. Muscular and glandular esophagus 0,52 and 1,44 $\mathrm{mm}$ long, respectively. Nerve ring 230-260 from anterior end. Vulva 9,80-10,08 $\mathrm{mm}$ from anterior extremity; ovijector 280 long. Eggs 36 long by 18-21 wide. Rectum 72-79 long. Anus 140-160 from posterior end.

Taxonomic summary:

Host: Sporophila caerulescens caerulescens (Vieill., 1817), Fringillidae (Common name: Double-collorad seedeater, coleirinho).

Site - gizzard.

Locality - State of Rio de Janeiro, Brazil.

Specimens deposited - CHIOC no. 32,848 a-h (whole mounts).

Remarks : This species was described from Cyanocorax chrysops (Vieill.), Corvidae, captured in Paraguay (LENT, FREITAS \& PROENÇA, 1945). In Brazil, a single species of the genus, namely $A$. mammilaris (Molin, 1860) Railliet, Henry \& Sisoffi, 1912, was proposed from a Corvidae from Manaus, State of Amazonas as Dispharagus mammilaris, with basis on female specimens. Thus, this is the second report of the genus and the first of the species in Brazil and a new host record.

\section{Onchocercidae Leiper, 1911 Aproctella stoddardi Cram, 1931}

Figs 8-13

Redescription (based on six mature males and three mature females). General: small worms tapering markedly at extremities. Oral opening circular, bordered by weakly cuticularized ring. Buccal capsule moderately well developed. Lateral walls of buccal capsule bearing weakly cuticularized projections which protrude prominently from oral opening forming delicate, rounded lip-like structures. Esophagus short, undivided.

Male (Figs 10, 12, 13): 9,45-9,94mm long, 150-210 wide. Esophagus 410-540 long. Nerve ring 120-160 from anterior end. Spicules stout, curved. Right spicule 72-75 long, left spicule 80-93 long. Caudal papillae absent. Cloacal aperture 61-79 from posterior end.

Female (Figs 8, 9, 11): 13,60-15,30mm long, 270-360 wide. Esophagus 460-500 long. Nerve ring 140 from anterior end. Vulva 770-910 from anterior 


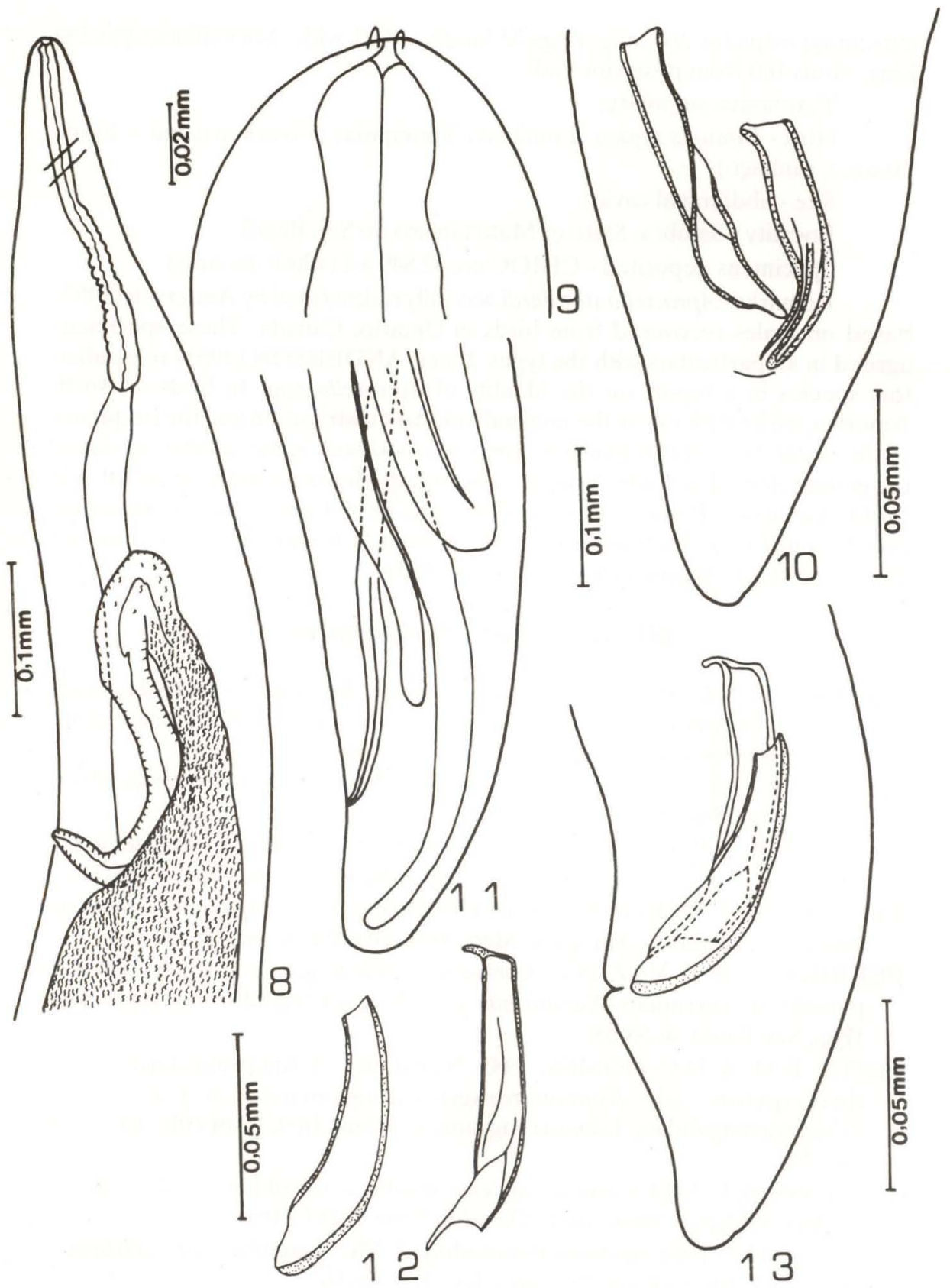

Figure 8-13. Aproctella stoddardi. (8) female, anterior portion, lateral view; (9) female, anterior end, lateral view; (10) male, posterior portion, frontal view; (11) female, posterior portion, lateral view; (12) spicules, latero/frontal view; (13) male, posterior portion, lateral view. 
extremity; ovijector 360 long. Eggs 25 long by 14-21 wide. Microfilarie 230-250 long. Anus 100 from posterior end.

Taxonomic summary:

Host - Thraupis sayaca (Linnaeus), Thraupidae (Common name $=$ Sayca tanager, sanhaço).

Site - abdominal cavity.

Locality - Salobra, State of Mato Grosso do Sul, Brazil.

Specimens deposited - CHIOC no. 32,849 a-i (whole mounts).

Remarks - Aproctella stoddardi was fully redescribed by Anderson (1957) based on males recovered from birds in Ontario, Canada. These specimens agreed in all particulars with the types. Later, ANDERSON (1961) reestudied this species in a report on the identity of Aproctella spp. In birds in North America, with emphasis on the unusual wide host distribution and the frequency of the occurrence of this filarioid. Aproctella stoddardi is the second species of the genus referred in South America. The first species reported from Brazil, was Carinema carinii Pereira \& Vaz, 1933, and later transferred to Aproctella (Anderson, 1957). The type host of this species is Bonasa umbellus from the United States of America (YAMAGUTI, 1961).

\section{BIBLIOGRAPHIC REFERENCES}

ANDERSON, R.C. 1957. Taxonomic studies on the genera Aproctella Cram, 1931 and Carinema Pereira and Vaz, 1933, with a proposal for a new genus Pseudaproctella n.gen. Can. J. Zool. 35: 25-33.

- 1961. On the identity of Aproctella in birds in North America. Proc. Helminthol. Soc. Wash. 28: 81-82.

BAYLIS, H.A. \& R. DAUBNEY 1922. Report of the parasite nematodes in the collection of the zoological survey of India. Mem. Indian Mus. 7: 263-347.

LENT, H.; J.F.T. FREITAS \& M.C. PROENÇA 1945. Alguns helmintos de aves colecionadas no Paraguai. Mem. Inst. Oswaldo Cruz 43: 271-285.

PEREIRA, C. \& Z. VAZ 1933. Carinema carinii n. gen. e n. sp. de filarídeo parasito de corrupião (Xanthornus sp.) pássaro fringilliformes. Rev. Biol. Hyg., São Paulo, 4: 56-58.

PINTO, R.M. \& D.C. GOMES. 1985. Nematodes of Amazonas birds with a description of Hoazinstronsgylus amazonensis n.gen. n.sp. (Trichostrongylidae, Libyostrongylinae). Mem. Inst. Oswaldo Cruz 80: 213-217.

TRAVASSOS, L. 1913. Sobre as espécies brasileiras da subfamilia Heterakinae Railliet \& Henry. Mem. Inst. Oswaldo Cruz 5: 217-318.

YAMAGUTI, S. 1961. Systema Helminthum 3. The nematodes of vertebrates

New York, Interscience Publisher Inc., II + 1261p. 